\title{
Virtual Training Centre for Computer Numerical Control
}

\author{
M. Sahin, S. Yaldiz, F. Unsacar, B. Yaldiz, N. Bilalis, E. Maravelakis, A. Antoniadis
}

\begin{abstract}
:
It is a fact that virtual training has been a scope of interest for vocational training for a very long time. However, it needs more time to be more common in all specific training fields. Focusing on Computer Numerical Control (CNC) Training, new developments in the CNC machinery produce a continuous demand on enhancing the programming and technical capabilities of the involved personnel. Training on CNC should follow similar developments and in particular in their programming capabilities, automation they offer and their technical capabilities. Based on these main objectives a Virtual Training Center (VTC) for CNC has been developed and it is presented in this paper. The VTC is the main result of a multilateral Leonardo Da Vinci project witch aims to promote and reinforce Vocational Training in CNC Machines. Keywords: Virtual training center, CNC, VET.
\end{abstract}

\section{Introduction}

In most Member States the past two decades there has been a growing awareness of the importance of quality in vocational education and training (VET). The changing demands of the knowledge-based society and the overall trend to increase the efficiency and effectiveness of VET systems, constitute major driving forces behind these developments. Major European funding frameworks and programmes, such as Leonardo Da Vinci (LdV) have contributed to improving education and VET systems by raising the level of the services they offer.

One of the objectives of the innovative VET systems is the transparency and distribution of information. This function concerns the potential and actual use of information. There may be different systems and structures of information distribution among the various actors, and in the public and there are preconditions for creating transparency in the VET system. To improve quality there must be systems for distributing information and certain mechanisms to ensure the circulated information can be used by the various actors in the policy process. The more widespread the distribution, the better the potential use of the data will be - and as a reversal effect, better quality data can be expected, as the actors are able to check the information against their experience and will provide feedback to the systems for gathering data.

One of the concrete future strategic objectives of education and training systems in the EU (Council of the European Union, 2001) is the improvement of the quality and the effectiveness of education and training systems in the EU. This includes improving education and training for teachers and trainers, developing skills for the knowledge society, ensuring access to ICT for everyone, increasing recruitment to scientific and technical studies, and making the best use of resources. The second strategic objective is facilitating the access of all to education and training systems. This objective includes open learning environment, making learning more attractive, and supporting active citizenship, equal opportunities and social cohesion. This paper describes the main results of a LdV project that addresses the strategic objectives mentioned above.

\section{From the Blackboard to the Virtual Training Centre}

During the 60's and 70's, teaching and learning tools were nothing but a piece of chalk and a blackboard eraser, teachers and students who met each other face to face inside the classroom during class. 
In the 80 's, videotape programs were used as teaching aids. In the 90's, one-way teaching by computer arrived. And finally today's advanced computer and information network technology has introduced radical innovative breakthroughs in our teaching and learning methods as well as in the learning environment. Students can listen to their teacher or trainers in distant classrooms through PC's and get a simultaneous view of their teachers and texts as well. They can ask questions and record the "class" for repeated viewing. Training organizations can conduct professional training directly via the computer network. These learning environments are not so different from a teacher-guided class with discussions and tests as well.

In the report "Studies in the context of the E-learning Initiative: Virtual Models of European Universities" [1] a key concern was how virtual mobility is being supported in European universities through ICT integration and e-learning. The study found that the majority of universities face major challenges in promoting ICT integration. ICT strategy is very important and those universities that have an ICT strategy are significantly ahead in integration of ICT in administration and organisation and networking. Integration of ICT and e-learning is politically important in the EU in terms of internationalisation and globalisation of education, student demand and interest in increasing the quality of education through ICT [2], [3], [4]. At the national level, integration of ICT should become a key priority with national and regional institutions making a commitment to ITC and the development of networks. There must be increased national flexibility with a commitment to support common standards of quality and assessment and to develop national and international metadata standards.

In the last 3 decades, a large number of vocational training centres and technical universities are giving priority to CNC Training. New developments on CNC machines are providing a continuous need for updated CNC training curriculum. Training on CNC should follow similar developments and in particular in their programming capabilities, automation they offer and their technical capabilities. In addition, $\mathrm{CNC}$ programming is becoming more and more automated through the use of CAD/CAM systems. This requires from the programmers to acquire CAD operation capabilities, on top of their $\mathrm{CNC}$ operation and programming knowledge. The major objective in the field of CNC training is to improve the qualifications and competences of the trainees, which is directly related to a well-designed and effective curriculum to be carried out on CNCs. The facilities for CNC training vary a lot and this has had direct impact on the experience that the trainee is acquiring during his/her apprentice. This paper presents the development and promotion of a Virtual Training Centre (VTC), an internet based e-learning facility, specifically based on Computer Numerical Control (CNC) training. This centre includes a virtual space (a CNC training portal) on the Internet which allows the constant sharing of e-learning based CNC teaching material, which is created so as to foster the further development of e-learning based CNC educational contents. This virtual training centre aims at setting the standard CNC virtual learning in vocational training systems [5]. 


\section{Developing a common CNC Curriculum}

During the first stages of the project, the equipment, methods, curriculum and techniques currently used for CNC training by the organisations in the partner countries were observed, collected and evaluated [6], [7]. The selected materials were used to create a new and common curriculum. Five important factors that contribute to learning were taken into account in order to prepare the $\mathrm{CNC}$ curriculum:

- Motivation

- Aptitude

- Presentation

- Repetition

- Practice with reinforcement

The approach for developing the appropriate training material was based on the following key concepts:

- Motivation

- Know your machine (from a programmer's viewpoint)

- Prepare to write programs

- Understand the motion types

- Know the compensation types

- Format your programs in a safe, convenient, and efficient manner

- Know the special features of programming

- Know your machine (from an operator's viewpoint)

- Understand the three modes of operation

- Know the procedures related to operation

- You must be able to verify programs safely

This approach combined with the important learning factors finally led to a CNC training curriculum including 28 sessions:

1. Machine configuration

2. Speeds and feeds

3. Visualizing program execution

4. Understanding program zero

5. Measuring program zero

6. Assigning program zero

7. Flow of program processing

8. Introduction to programming words 
9. Preparation for programming

10. Types of motion

11. Introduction to compensation

12. Dimensional (wear) tool offsets

13. Geometry offsets

14. Tool nose radius compensation

15. Program formatting

16. The four kinds of program format

17. Simple canned cycles

18. Rough turning and boring multiple repetitive cycle

19. More multiple repetitive cycles

20. Threading multiple repetitive cycle

21. Subprogramming techniques

22. Control model differences

23. Other special features of programming

24. Control model differences

25. Machine panel functions

26. Three modes of operation

27. The key operation procedures

28. Verifying new programs safely

\section{The structure of the Virtual Training Centre}

To develop the virtual training centre, firstly, a communication website was developed in order to manage the activities and tasks to be carried out by the partners. Then, an interactive teaching program was developed and put into a website to form a virtual training centre (figure 1).

The common curriculum developed for this purpose was the base of this training centre. The site, along with the interactive teaching program, was divided into four main areas, "News", "Exchange of views", "Projects and Networks", and "Information Resources". With these, users would be able to access a newsletter, a bulletin board, online surveys and survey reports, information on VET networks, an electronic library with references, a bookshop with downloadable publications and a number of databases. 


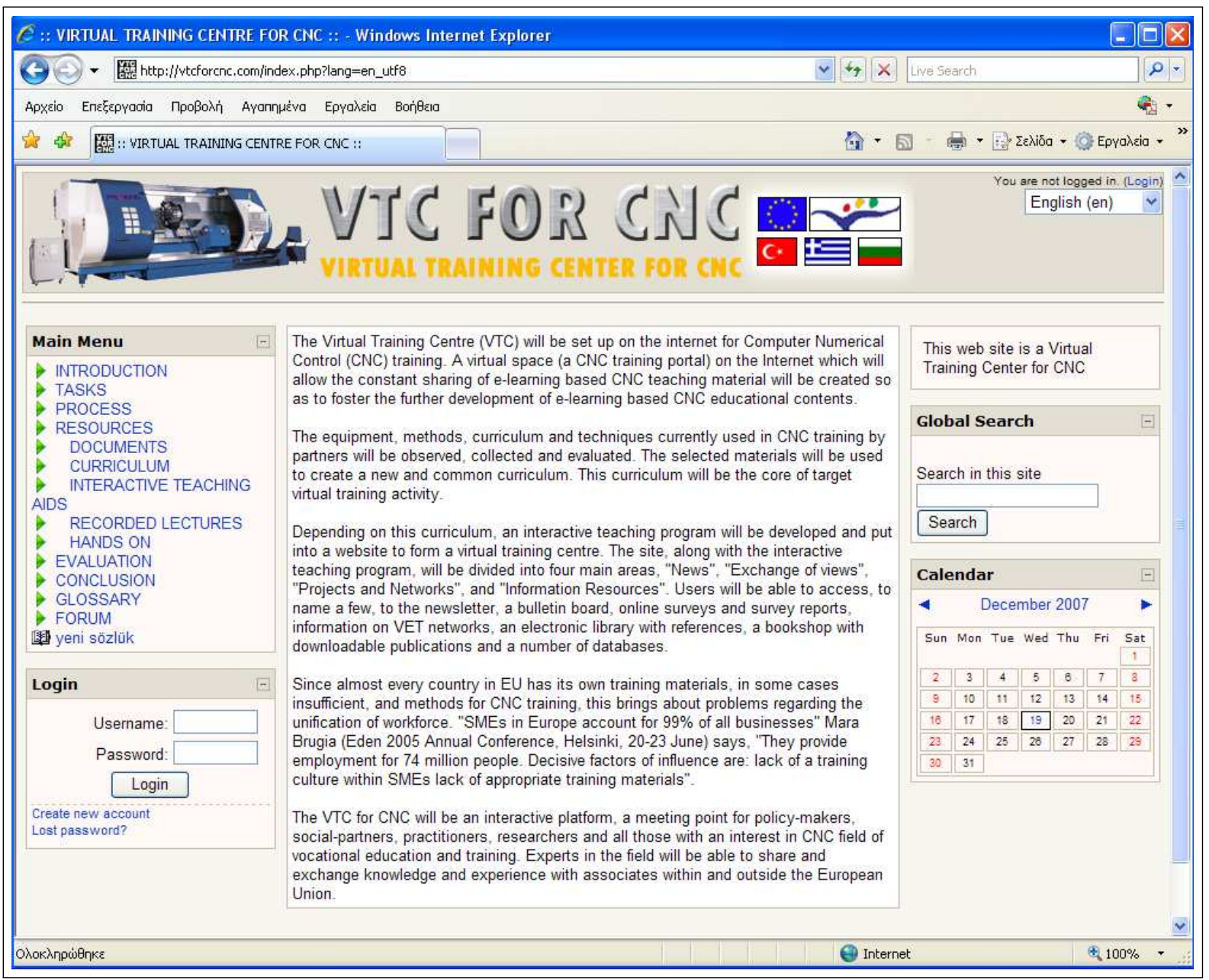

Figure 1: The interface of the interactive $\mathrm{CNC}$ training centre (http://www.vtcforcnc.com)

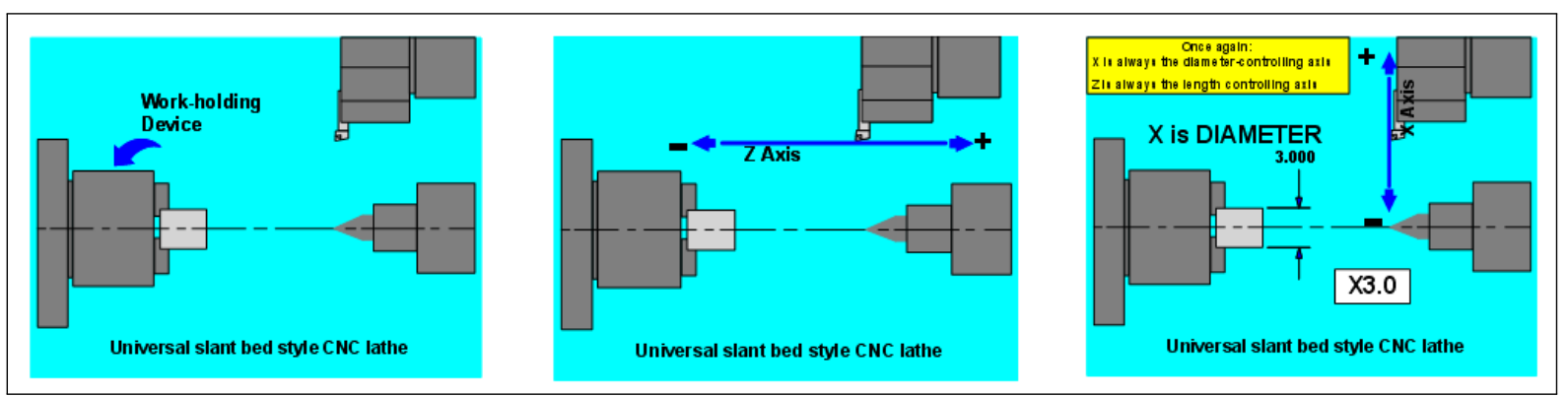

Figure 2: Example of 3- phase animated CNC training material 
In the main core of the $\mathrm{CNC}$ training material, simulations and practical exercises are included into the interactive training centre (figure 2).

The feedback of the implementation of the VTC in training centres has been recorded and evaluated in order to produce the final version. The evaluation procedure included content (topics, language used, modules), methods (progress, different levels of difficulty, and range of resources, situations and practical cases) and technology (ease of installation, interactive nature and use without a tutor).

The main aim of the VTC for CNC aims is to be an interactive platform, a meeting point for policymakers, social-partners, practitioners, researchers and all those with an interest in CNC field of vocational education and training. Experts in the field are able to share and exchange knowledge and experience with associates within and outside the European Union. This will foster the long-term viability of the Centre.

\section{Aims and Target Groups of the VTC}

The VTC aims to improve the skills and competences of people to promote and reinforce the contribution of vocational training to the process of innovation, with a view to improving competitiveness and entrepreneurship, also in view of new employment possibilities.

The specific aims of VTC can be defined as follows:

- Training the trainers, trainees, technicians and apprentices and all enthusiastic about CNC.

- Preparing technicians as intermediates having common measurable qualities the industry is seeking.

- Helping to form a labour force that can use current knowledge and technology, and thus, in search for life-long learning.

- Supporting the sectoral communication through the national centres in partners.

- Setting up a website to publish the data collected.

- Adapting the collected materials to enhance the new curriculum satisfying the requirements in a modern sense.

- Helping to improve and upgrade competences and skills of the involving institutions' didactic staff and exchange experiences over the virtual training centre.

- Enabling the participants to extend the common educational qualifications of CNC technologies, the accreditation of the skills and knowledge of CNC technologies acquired within the network created between participating institutions and organizations.

- Increase the quality of employment through qualified workers.

- Helping to increase active use of technology acquired and thus to increase the standards.

- Contributing to individuals by behaving through life long learning.

- Having a labour power in accordance with common design and production standards.

- Contributing to labour market by using the common technology and equipment effectively. 
- Helping to enhance available potential of human sources.

Target groups include trainers, trainees, technicians, apprentices and all enthusiasts about CNC. The final and potential users of the project's results are the training organisations, the SMEs dealing with metal products by $\mathrm{CNC}$ usage, and the universities, colleges, vocational schools, training centres.

\section{Conclusions}

The integration of ITC in this virtual learning environment for CNC, the development of the VTC and the common training curriculum are focused on the EU goals of of internationalisation and globalisation of education, student demand and interest in increasing the quality of education through ICT. At the national level, integration of ICT should become a key priority with national and regional institutions making a commitment to ITC and the development of networks. There must be increased national flexibility with a commitment to support common standards of quality and assessment and to develop national and international metadata standards. This centre addresses the priorities expressed here. Furthermore, this Virtual Training Centre addresses the strategic objectives mentioned above: improving the quality and effectiveness of education and training systems in the EU by developing skills for the knowledge society, ensuring access to ICT for everyone, increasing recruitment to scientific and technical studies, and making the best use of resources. Facilitating the access of all to education and training systems by providing open learning environment, making learning more attractive, and supporting active citizenship, equal opportunities and social cohesion is the other strategic objective that can be achieved through this virtual training centre. The experiences and knowledge gained during the implementation of this Centre can be used in developing and improving other training programmes in particular in the area of new information technology applications in related sectors.

\section{Bibliography}

[1] Ramboll, PLS: Studies in the context of the E-learning Initiative: Virtual Models of European Universities (Lot1). Draft Final Report to the European Commission, DG Education and Culture. Available at http://elearningeuropa.info Available at http://elearningeuropa.info, 2004.

[2] A. Andreatos, Virtual Communities and their Importance for Informal Learning, International Journal of Computers, Communications \& Control, Vol. II, No. 1, pp. 39-47, 2007.

[3] A. Styliadis, I. Karamitsos, D. Zachariou, Personalized e-Learning Implementation - The GIS Case, International Journal of Computers, Communications \& Control, Vol. I, No. 1, pp. 59-67, 2007.

[4] C. Zhengxin, Learning about Learners: System Learning in Virtual Learning Environment, International Journal of Computers, Communications \& Control, Vol. I (2008), No. 1, 2007.

[5] M. Sahin, N. Bilalis, S. Yaldiz, A. Antoniadis, F.Unsacar, E. Maravelakis, Revisiting CNC Traininga Virtual Training Centre for CNC International Conference on E-Portfolio Process in Vocational Education-EPVET, Bucharest, Romania, 2007.

[6] W. Xiaoling, Z. Peng, W. Zhifang, S. Yan, L. Bin, L. Yangchun, Development an interactive VR training for CNC machining, International Conference on Virtual Reality Continuum and its Applications in Industry, Proceedings VRCAI 2004 - ACM SIGGRAPH, pp. 131-133, 2004.

[7] L. Yadong, G. Xingui, L. Wei, Y. Kazuo , K. Keizo and M. Fujishimab, An intelligent NC program processor for CNC system of machine tool, Robotics and Computer-Integrated Manufacturing, Vol 23 (2), pp 160-169, 2007. 
Mehmet Sahin, Suleyman Yaldiz, Faruk Unsacar, Burak Yaldiz Technical Science College Selcuk University 42031 Konya, Turkey E-mail: mesahin,syaldiz,funsacar@selcuk.edu.tr

Nikolaos Bilalis Department of Production Engineering \& Management Technical University of Crete 73100, Chania, Greece E-mail: bilalis@dpem.tuc.gr

Emmanuel Maravelakis, Aristomenis Antoniadis Department of Natural Resources \& Environment Design \& Manufacturing Laboratory Technological Educational Institute of Crete 73133 Chania, Greece

E-mail: marvel,antoniadis@chania.teicrete.gr

Received: December 20, 2007 